\title{
Field Application of the Mycorrhizal Fungus Rhizophagus irregularis Increases the Yield of Wheat Crop and Affects Soil Microbial Functionalities
}

\author{
Sanâa Wahbi1,2, Yves Prin'3, Tasnime Maghraoui1,4, Hervé Sanguin33, Jean Thioulouse5, \\ Khalid Oufdou ${ }^{4}$, Mohamed Hafidi², Robin Duponnois ${ }^{{ }^{*}}$ \\ ${ }^{1}$ IRD, UMR LSTM, Montpellier, France \\ ${ }^{2}$ Laboratoire Ecologie \& Environnement (Unité Associée au CNRST, URAC 32), Faculté des Sciences Semlalia, \\ Université Cadi Ayyad, Marrakech, Maroc \\ ${ }^{3}$ CIRAD, UMR LSTM, Montpellier, France \\ ${ }^{4}$ Laboratoire de Biologie et de Biotechnologie des Microorganisms, Faculté des Sciences Semlalia, Université \\ Cadi Ayyad, Marrakech, Maro \\ ${ }^{5}$ Laboratoire de Biométrie et Biologie Evolutive, Université Lyon 1, Villeurbanne, France \\ Email: "Robin.Duponnois@ird.fr
}

Received 30 October 2015; accepted 13 December 2015; published 16 December 2015

Copyright (C) 2015 by authors and Scientific Research Publishing Inc.

This work is licensed under the Creative Commons Attribution International License (CC BY).

http://creativecommons.org/licenses/by/4.0/

(c) (i) Open Access

\begin{abstract}
The aim of this study was to test the impact of Rhizophagus irregularis, an arbuscular mycorrhizal fungus (AMF), on durum wheat growth and soil microbial functionalities in a field inoculation trial conducted in Morocco. The results showed that i) the $R$. irregularis inoculum effectively improved wheat growth, ii) wheat growth promotion depended on the soil mycorrhizal infectivity and iii) functional abilities of soil microflora depended on AMF inoculation. This study confirms that field AMF inoculation can be proposed as an effective agronomic practice in wheat production and as a sustainable cultural practice to manage soil biofunctioning. To fully promote inoculation practices, a better knowledge of AMF ecology has to be acquired to better adapt AMF inoculation to environmental conditions, and thus warrant better yields and agricultural sustainability.
\end{abstract}

\section{Keywords}

Arbuscular Mycorrhizal Fungi, Field-Grown Wheat, Mycorrhizal Field Inoculation, Nutrient Uptake, Microbial Soil Functions

\footnotetext{
${ }^{*}$ Corresponding author.
}

How to cite this paper: Wahbi, S., Prin, Y., Maghraoui, T., Sanguin, H., Thioulouse, J., Oufdou, K., Hafidi, M. and Duponnois, R. (2015) Field Application of the Mycorrhizal Fungus Rhizophagus irregularis Increases the Yield of Wheat Crop and Affects Soil Microbial Functionalities. American Journal of Plant Sciences, 6, 3205-3215. http://dx.doi.org/10.4236/ajps.2015.619312 


\section{Introduction}

It is well known that Arbuscular Mycorrhizal Fungi (AMF) play a major role in the biofunctioning of natural and agricultural ecosystems. AMF form symbiotic relationships with most of indigenous and cultivated plant species in terrestrial environments by increasing the nutrient uptake efficiency of plants in exchange of photosynthetically fixed carbon [1]. In addition to these nutritional benefits, AMF are also known to increase soil structure, reduce diseases, affect the diversity of plant communities [2]-[4] and influence relationships between plants [5]-[7]. In addition, mycorrhizal symbiosis alters root functions and microbial equilibrium in the rhizosphere [8] [9]. This zone influenced by both the roots and the mycorrhizal symbiont has been named "mycorrhizosphere" [10] [11] and included the more specific term "hyphosphere" which only referred to the zone surrounding individual fungal hyphae [12]. The "mycorrhizosphere effect”, resulting from fungal activities, modifies the structure and the functionalities of soil microbial communities [13]. Numerous studies have reported that AMF and soil microflora can interact synergistically leading to plant growth stimulation [14].

Hence AMF offer a large potential to increase agricultural yields and productivity in a low-input manner. However, a significant part of the knowledge about AMF functions results from laboratory experiments in which plants are cultivated in sterilized soil inoculated or not with particular AMF strains. This experimental approach excludes indigenous AMF that could alter plant response or compete with the AMF inoculant [15] [16]. In addition, these studies ignore the functional complexity of the soil biological community that could interact with the fungal inoculant and influence the establishment of the AMF symbiosis and its impact on the plant development [17] [18].

Wheat is one of the most important cereal crops in the world in terms of cultivated area [19] and durum wheat (Triticum turgidum L. var durum) is the main cereal grown in the Mediterranean regions [20]. It is mostly grown under stressful conditions in the Mediterranean region, where drought and heat stress usually constrain yield potential during the grain filling period [21]. Wheat is classified as non-mycotrophic or mycotrophic depending on the cultivars [22]. Although many field studies have addressed the possibility of increasing wheat nutrient uptake, growth and yield by AMF inoculation [23], very few have been performed along the south side of the Mediterranean Basin and more particularly in Morocco. In addition, little is known with regards to the impacts of AMF application on the native soil microbial functions.

In the present study, we conducted a field trial aiming to answer to the following questions:

1) Does AMF inoculation increase wheat growth, nutrient uptake and grain yield?

2) Are an increased mycorrhizal colonization and an extended soil hyphal length linked to changes in wheat growth, nutrient uptake and grain yield?

3) Is the impact of AMF inoculation on wheat growth, nutrient uptake and grain yield dependent on the native AMF abundance and infectivity (mycorrhizal soil infectivity)?

4) Does AMF inoculation impact the native soil microbial functions involved in the main soil geochemical cycles $(\mathrm{P}$ and $\mathrm{N})$ ?

\section{Materials and Methods}

\subsection{Field Conditions and Experimental Design}

A field trial was performed in the 2011-2013 growing seasons in the Haouz plain at about $30 \mathrm{~km}$ at the West of Marrakech (31 ${ }^{\circ} 60^{\prime \prime} \mathrm{N}$ and $7^{\circ} 3^{\prime} 0^{\prime \prime} \mathrm{W}$, Morocco). Soil chemical properties ( 0 - $0.10 \mathrm{~m}$ layer) were as follows: $\mathrm{pH}$ $\left(\mathrm{H}_{2} \mathrm{O}\right)$ 7.2; carbon (\%) 1.54; nitrogen (\%) 0.08, C/N 19.2; Total P (mg.kg ${ }^{-1}$ ) 502.9 and Olsen P (mg.kg $\left.{ }^{-1}\right) 22.1$. The climate of the experimental site is semiarid Mediterranean, with a mean annual rainfall of $282 \mathrm{~mm}$, mostly in Autumn/Winter (59\%) and in Spring (22\%). The dry season is from May to September. The mean air temperature is $17.9^{\circ} \mathrm{C}$ in Autumn, $12.8^{\circ} \mathrm{C}$ in Winter, $18.5^{\circ} \mathrm{C}$ in Spring, and $24.7^{\circ} \mathrm{C}$ in Summer. Soil, cropped in the previous growing season with durum wheat (Triticum durum Desf.), was plowed to a depth of $0.30 \mathrm{~m}$ in Summer and then shallowly harrowed to control weeds. No herbicide nor chemical fertilizers were applied. The experimental design had a randomized block design with one factor and four replication blocks. The factor was the direct AMF inoculation or not (control). Plots were $3.0 \mathrm{~m} \times 3.0 \mathrm{~m}$; each main plot was spaced $1.0 \mathrm{~m}$ out from the next. Inoculation with AMF included the application of the commercial AMF inoculum (Inoculum plus ${ }^{\mathrm{TM}}$ ). This spore inoculum including $R$. irregularis $\left(2 \times 10^{4}\right.$ spores per gram of inoculum) and peat was mixed with a disinfected sand $\left(120^{\circ} \mathrm{C}, 20 \mathrm{~min}\right)$ to obtain a total spore density of $40 \mathrm{spores}^{\circ} \mathrm{g}^{-1}$. 
Durum wheat was sown in December 2011 and 2012 at a rate of 400 viable seeds $\cdot \mathrm{m}^{-2}$ in rows $0.18 \mathrm{~m}$ apart. The experimental plot consisted of four rows $3 \mathrm{~m}$ long. Weeds were controlled by hand during the experiment. At sowing, five grams of the AMF inoculum (200 spores of $R$. irregularis) were placed in each planting rows at $0.20 \mathrm{~m}$ intervals.

\subsection{Plant Analysis}

After one and two growing seasons, at wheat tillering, the total number of wheat plant and spike per plot were counted. Then ten randomly chosen plants in the middle of the plot were harvested. The seeds from each plant were collected, counted and weighed to determine the dry weight of 1000 seeds (grain yield). The aerial parts of each plant were then oven dried at $70^{\circ} \mathrm{C}$ during 2 weeks and weighed. After drying, shoot tissues were ground, ashed $\left(500^{\circ} \mathrm{C}\right)$, digested in $2 \mathrm{ml} \mathrm{HCl} 6 \mathrm{~N}$ and $10 \mathrm{ml} \mathrm{HNO}_{3} \mathrm{~N}$ for nitrogen and then analyzed by colorimetry for phosphorus [24]. For nitrogen determination (Kjeldahl method), they were digested in $15 \mathrm{ml} \mathrm{H}_{2} \mathrm{SO}_{4}$ (36 N) containing $50 \mathrm{~g} \cdot \mathrm{l}^{-1}$ of salicylic acid. Roots from five other randomly chosen plants in the middle of each plot were sampled and root subsamples of about $3 \mathrm{~g}$ each were taken. Each subsample was stained with $0.05 \%$ trypan blue in lactic acid according to Phillips and Hayman [25]; root colonization by AMF was then measured with the grid intersect method according to Giovannetti and Mosse [26].

Inoculation effectiveness (IE) of AMF inoculation on plant yield was calculated based according to the following formula:

$$
\mathrm{IE}=[(\text { yield }(+\mathrm{M})-\text { yield }(-\mathrm{M})) / \text { yield }(+\mathrm{M})] \times 100
$$

with $+\mathrm{M}$, inoculated plants; $-\mathrm{M}$, non-inoculated plants.

\subsection{Soil Microbial Analysis}

After one and two growing seasons, soil cores $(1 \mathrm{~kg})$ were collected at 0 - to 10 -cm depth in each plot. About 10 soil samples were taken from each plot and pooled together. Soil samples were crushed and passed through a 2-mm sieve. Then hyphal length was measured by the filtration-grid-line method [27].

Patterns of in situ catabolic potential (ISCP) were designed to determine the functions of soil microbial communities and the microbial functional diversity in soil treatments after one and two growing seasons [28]. With a micro-respirometry method carried out in 96-well microtiter plates [29], 28 organic substrates (3 wells per substrate) were tested; Thirteen carbohydrates (D-mannose, D-mannitol, D-trehalose, L-arabinose, D-xylose, Dsucrose, D-galactose, meso-inositol, D-sorbitol, L-rhamnose, L-arabitol, mesoerythriol, D-Glucose), 8 carboxylic acids (citric acid, maleic acid, D,L-malic acid, oxalic acid, Na-glucomate, $\alpha$-ketoglutaric acid, L-ascorbic acid) and 7 amino acids (L-asparagine, D,L-valine, L-methionine, L-glutamine, D,L-alanine, D,L-serine, Nacetyl-D-Glucosamine). Detection plates were prepared according to the MicroResp ${ }^{\mathrm{TM}}$ recommendations, and data were recorded by using a Tecan infinite M200 Plate Absorbance reader (Absorbance measured at $572 \mathrm{~nm}$ ). For each well, the absolute respiratory activity was determined by subtracting the absorbance value at t0 to the value after 6 days of incubation at $27^{\circ} \mathrm{C}$ in the dark (t6). The average basal respiration value was then subtracted to all the individual substrate respiration values. For each organic substrate, the substrate-specific respiratory activity was averaged and the value was finally divided by the sum of all the mean substrate specific respiratory activities ( $\mathrm{p}_{\mathrm{i}}$ value). The catabolic evenness $(E)$ was calculated to determine the catabolic diversity of soil treatments. It represents the variability of catabolized substrates amongst the range of the targeted substrates and is calculated using the Simpson-Yule index $E=1 / \sum \mathrm{p}_{\mathrm{i}}^{2}$ with $\mathrm{p}_{\mathrm{i}}=$ (respiration response to individual substrates)/ (total respiration activity induced by all substrates for a soil treatment) [30]. The catabolic evenness could be used to evaluate the ability of microbial communities to resist against environmental stress or disturbance [30]. Data were calculated for the individual responses to substrates but also for the average responses with carbohydrates, carboxylic acids and amino acids.

\subsection{Assessment of the Mycorrhizal Soil Infectivity}

The mycorrhizal soil infectivity was estimated according to Kisa et al. [31]. Four dilutions of each soil sample were made by thoroughly mixing the original cultural soil substrate with the same soil but autoclaved $\left(120^{\circ} \mathrm{C}, 40\right.$ min). The levels of dilution (undisinfected soil/disinfected soil) were: 100\%, 50\%, 25\% and 0\% (v:v). Three 
replicates were prepared for each dilution. Seeds of durum wheat were surface sterilized with $10 \%$ sodium hypochlorite, washed with sterile distilled water $\left(120^{\circ} \mathrm{C}, 20 \mathrm{~min}\right)$ and pre-germinated for 2 days in Petri dishes on humid filter paper. One germinated seed was then transplanted into each of $100 \mathrm{~mL}$ pots filled with $100 \mathrm{~g}$ of different soil dilution. The pots were placed in a glasshouse under natural light (day length approximately $10 \mathrm{~h}$, mean temperature $22^{\circ} \mathrm{C}$ ) and watered daily with deionized water. After one month of growth, seedlings were uprooted and their entire root systems were washed under tap water. For each pot, the extent of AM colonization was assessed as described above.

\subsection{Statistical Analysis}

All the data were subjected to a two-way analysis of variance and comparisons among means were made using the Newman-Keuls test $(P<0.05)$. The percentages of the mycorrhizal colonization were transformed by arc$\sin ($ sqrt) before the statistical analysis. To evaluate the mycorrhizal soil infectivity, the relationships between the extent of AM colonization and soil dilutions were analyzed using mixed effects linear regression models. The p-values for model fits were obtained by ANOVA [32]. Computations were conducted with the R software [33], using the "NLME" package [34]. In the regression models, the fixed effects were the soil origin and the level of dilution (undisinfected soil/disinfected soil: 1, 1/2, 1/4, 0).

\section{Results}

\subsection{Wheat Nutrient Uptake, Growth and Grain Yield}

After one growing year, AMF application did not impact the total biomass yield, the spike number per ha, the dry weight of 1000 seeds (grain yield) (Table 1). In contrast, a positive effect of the AMF inoculation was recorded after two years of cultivation on the wheat growth and on the grain yield as well as the wheat phosphorus uptake (Table 1). The inoculation effectiveness was of $22.5 \%$ for the total biomass yield per ha, $29.3 \%$ for the spike number per ha and $7.7 \%$ for the grain yield (Table 1).

\subsection{Wheat Mycorrhizal Colonization and Soil Functionalities}

The mycorrhizal colonization of wheat plants and the hyphal length were not significantly impacted by the AMF inoculation after one growing year whereas they significantly improved after two growing seasons (Table 1 ).

After two years of cultivation, the catabolic evenness of the soils amended with the AMF inoculum were significantly higher than those calculated for the not inoculated treatments. The highest standardized average respi-

Table 1. Effects of $R$. irregularis application on total biomass yield $\left(\mathrm{kg} \cdot \mathrm{ha}^{-1}\right)$, spike number per ha, dry weight spike $\left(\mathrm{kg} \cdot \mathrm{ha}^{-1}\right)$, thousand-seed weight (TSW), mineral nutrition and mycorrhizal colonization of durum wheat one year (2012) and two years (2013) after the AMF inoculation in the field experiment located in the Haouz valley at about $30 \mathrm{~km}$ at the West of Marrakech (Morocco).

\begin{tabular}{|c|c|c|c|c|}
\hline & \multicolumn{4}{|c|}{ Treatments } \\
\hline & \multicolumn{2}{|c|}{ Control } & \multicolumn{2}{|c|}{$+R$. irregularis } \\
\hline & 2012 & 2013 & 2012 & 2013 \\
\hline Total biomass Yield $\left(\mathrm{kg} \cdot \mathrm{ha}^{-1}\right)$ & $4312(20.4)^{(1)} a^{(2)}$ & $4184(28.7) a$ & $4662(25.6) \mathrm{a}$ & $5401(71.6) \mathrm{b}$ \\
\hline Spike number per ha $\left(\times 10^{4}\right)$ & $177.1(27.5) \mathrm{a}$ & 167.3 (29.1)a & $227.7(18.8) b$ & $236.7(26.9) \mathrm{b}$ \\
\hline Thousand-seed weight & $42.3(2.5) \mathrm{a}$ & 41.7 (2.8)a & 42.7 (2.5)a & $45.2(2.5) \mathrm{b}$ \\
\hline Shoot N content (\%) & $\mathrm{nd}^{(3)}$ & $5.31(0.60) \mathrm{a}$ & nd & 5.39 (0.11)a \\
\hline Shoot $\mathrm{P}$ content $\left(\mathrm{mg} \cdot \mathrm{g}^{-1}\right.$ ) & nd & $6.25(0.91) a$ & nd & $7.62(0.29) \mathrm{b}$ \\
\hline Mycorrhizal colonization (\%) & 46.7 (5.8)a & 54.7 (4.7)a & $53.9(5.6) \mathrm{a}$ & 66.9 (3.9) b \\
\hline Hyphal length (m.g ${ }^{-1}$ dry soil) & $1.66(0.08) \mathrm{a}$ & $1.83(0.09) \mathrm{a}$ & $1.72(0.07) \mathrm{a}$ & $2.89(0.07) \mathrm{b}$ \\
\hline
\end{tabular}

${ }^{(1)}$ Standard error. ${ }^{(2)}$ For each year, data in the same line followed by the same letter are not significantly different according to the Newman-Keul's test $(p<0.05) .{ }^{(3)} \mathrm{nd}=$ not determined. 
ration SIRs (Substrate Induced Respirations) to amino-acids and carboxylic acids were recorded in the AMF inoculated treatments after 1 and 2 growing seasons except for the amino-acid group for the second growing year (Table 2). The AMF inoculation gave very different patterns of in situ catabolic potential (ISCP) (Figure 1). The substrates preferentially used in samples collected from the AMF treatments compared to the control were alanine, glutamine, asparagine, Na-glutamate, ascorbic acid, ketoglutaric acid, oxalic acid, gluconic acid, malic acid, maleic acid and citric acid for the first year of cultivation whereas for the secong growing season, the highest SIR responses were recorded in the AMF inoculated soil with ascorbic acid, ketoglutaric acid, malic acid, maleic acid and citric acid (Figure 1).

The regression model between the extent of AM colonization and soil dilutions for the four different treatments showed that the treatment and the percentage of soil dilution both had very strong effects $(P<0.0001)$. The differences between the control and the AMF inoculated treatment were only significant after two growing years $(P<0.001)$ (Figure 2).

\section{Discussion}

From the results of this study, the following three main points deserve discussion: i) whether the $R$. irregularis application was effective in improving the wheat growth, ii) whether the enhancement of wheat growth depended on the mycorrhizal soil infectivity and iii) whether functional abilities of soil microflora depended on AMF inoculation.

1) Field survey of wheat soils predicted that AMF would have the ability to colonize wheat roots at early stages of crop development [35] [36]. The positive effect of $R$. irregularis inoculation on wheat development is in accordance with previous studies where it has been shown that this fungal isolate was very efficient on the growth of other plant species in controlled conditions [31] [37] [38] and in field conditions [13]. In the present study, AMF field inoculation increased aboveground biomass (+22\%) supporting results from mycorrhizal pots experiments that show a mean increase of $18 \%$ [36] [39] [40]. Our results showed an increase of $18 \%$ for the P concentration in shoot biomass. This is in accordance with previous studies have reported that field AMF inoculation significantly increased P concentration in aboveground biomass (16\%) [23]. In our study, the variety of the wheat seeds was unknown as one of our objectives was to test the local seed resources usually used. It is well known that new varieties of many annual crops are more responsive to AMF colonization than ancestral genotypes [41]. It would be useful to compare the inoculation effectiveness on different durum wheat varieties and more particularly on wheat varieties in order to optimize the benefits expected from the AMF inoculation.

2) Positive wheat responses to AMF inoculation was positively correlated with the highest mycorrhizal root colonization root and the highest mycorrhizal soil infectivity. It has been reported that AMF inoculation increased root colonization by $29 \%$ leading to a significant plant biomass increase of $23 \%$ [17] [42]. These results suggest that the expected benefits on the crop yield mainly result from an increase in AMF abundance, rather than the introduction of new fungal strains [42]. Our results corroborate this evidence that inoculation efficiency is mainly related to abundance, rather than identity effects.

Table 2. Catabolic evenness and standardized average substrate-induced respiration (SIR) responses with each substrate group (carboxylic acids, amino-acids and carbohydrates) in the soils inoculated or not with Rhizophagus irregularis one year (2012) and two years (2013) after the AMF inoculation.

\begin{tabular}{ccccc}
\hline & \multicolumn{3}{c}{ Treatments } \\
\cline { 2 - 5 } & \multicolumn{3}{c}{ Control } & \multicolumn{2}{c}{+ R. irregularis } \\
\cline { 2 - 5 } & 2012 & $13.76(0.71) \mathrm{a}$ & $13.57(0.41) \mathrm{a}$ & $14.98(0.87) \mathrm{b}$ \\
Catabolic evenness & $12.38(1.75)^{(1)} \mathrm{a}^{(2)}$ & $0.019(0.005) \mathrm{a}$ & $0.033(0.066) \mathrm{a}$ & $0.026(0.002) \mathrm{b}$ \\
Carbohydrates & $0.025(0.005) \mathrm{a}$ & $0.008(0.002) \mathrm{a}$ & $0.146(0.035) \mathrm{b}$ & $0.009(0.002) \mathrm{a}$ \\
Amino-acids & $0.010(0.002) \mathrm{a}$ & $0.078(0.003) \mathrm{a}$ & $0.209(0.031) \mathrm{b}$ & $0.092(0.009) \mathrm{b}$ \\
\hline Carboxylic acids & $0.081(0.004) \mathrm{a}$ & 0.013 & \\
\hline
\end{tabular}

${ }^{(1)}$ Standard error. ${ }^{(2)}$ For each year, data in the same line followed by the same letter are not significantly different according to the Newman-Keul's test $(P<0.05)$. 


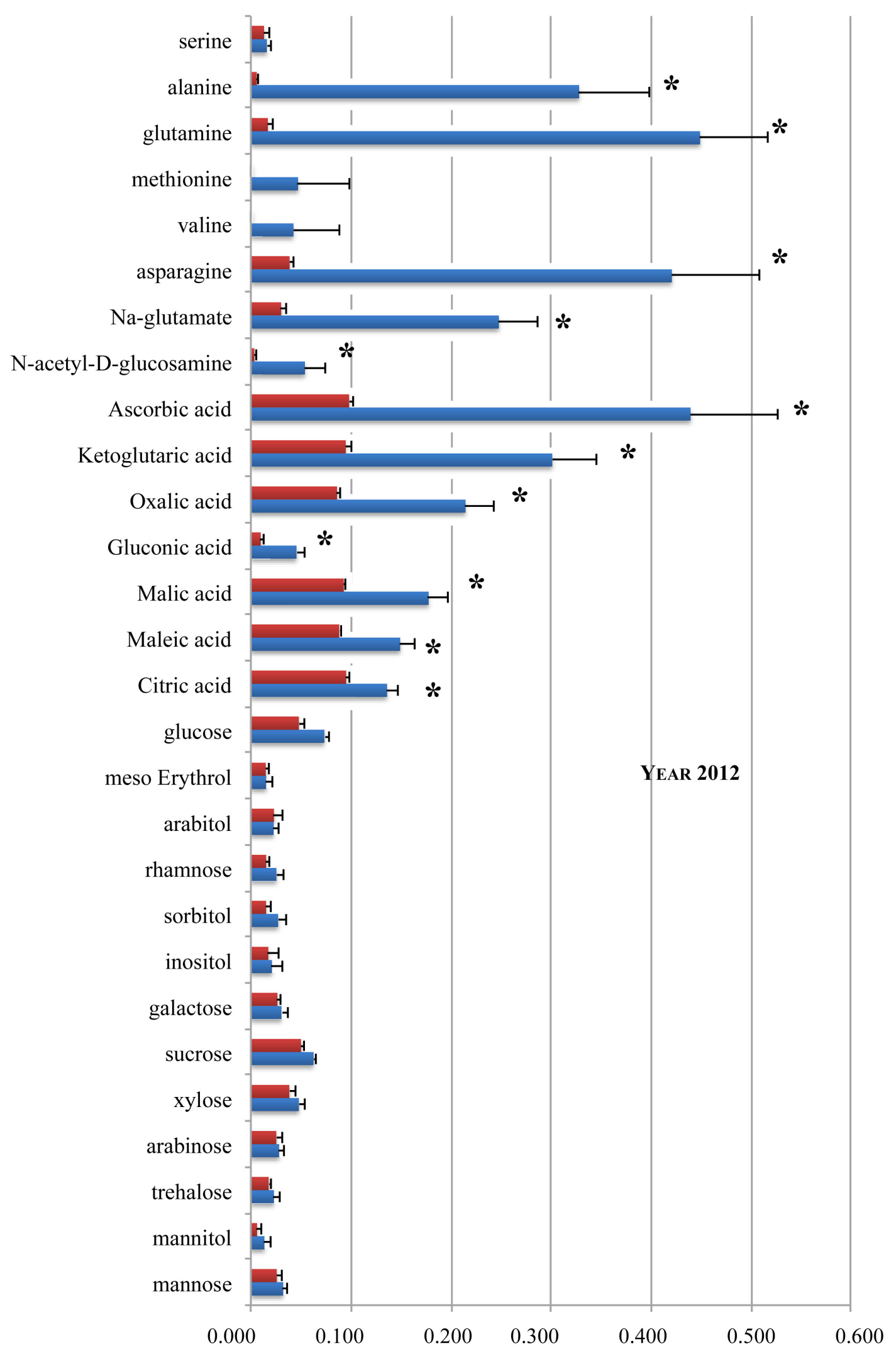

(a) 


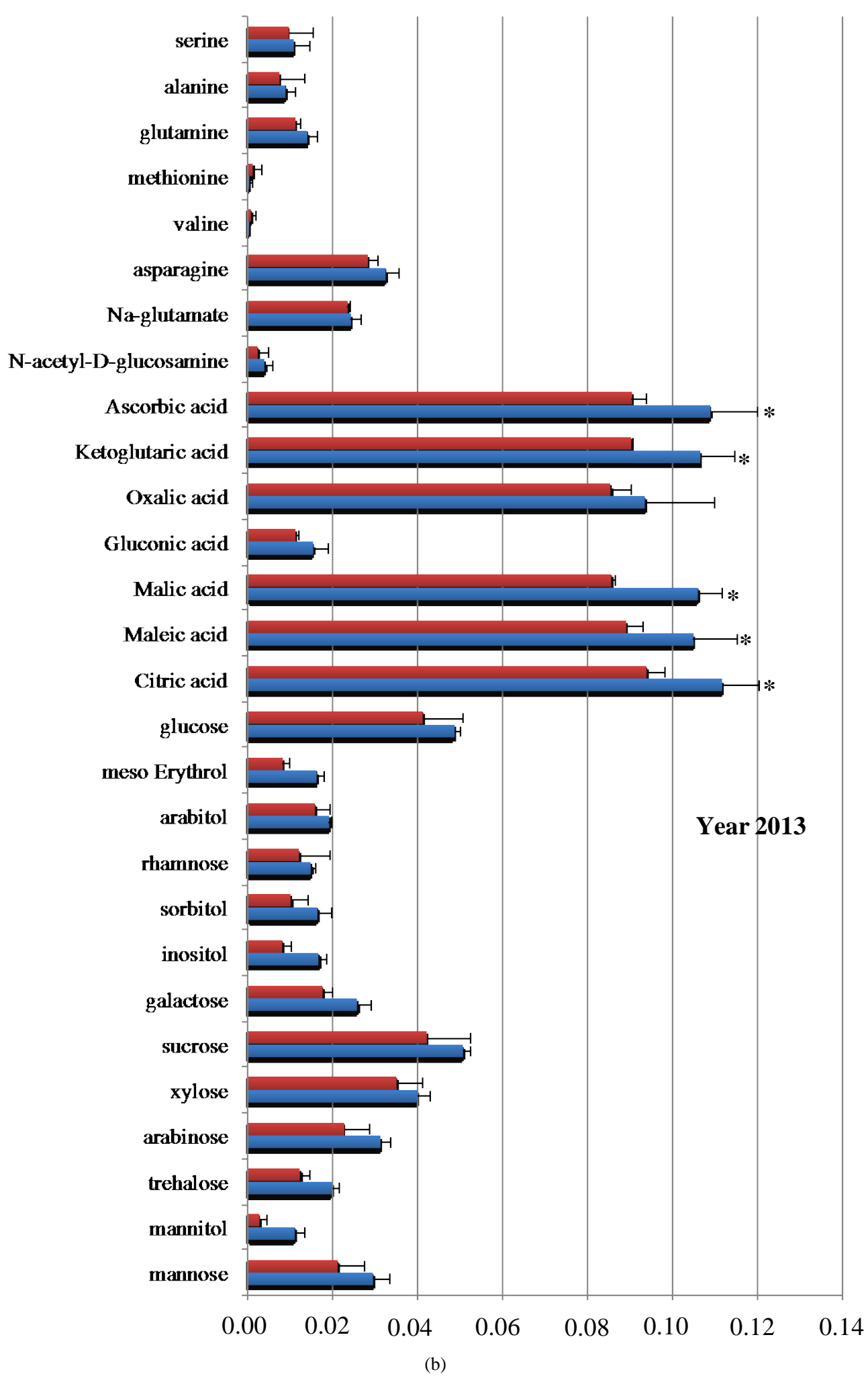

Figure 1. Catabolic response profiles for each soil origin one year (2012) and two years (2013) after the AMF inoculation. Error bars represent standard errors $(n=4)$. Blue bars, soil inoculated with Rhizophagus irregularis; Red bars, uninoculated soil. An asterisk indicates a significant difference between the two treatments, according to the Newman Keul's test $(P<0.05)$. 


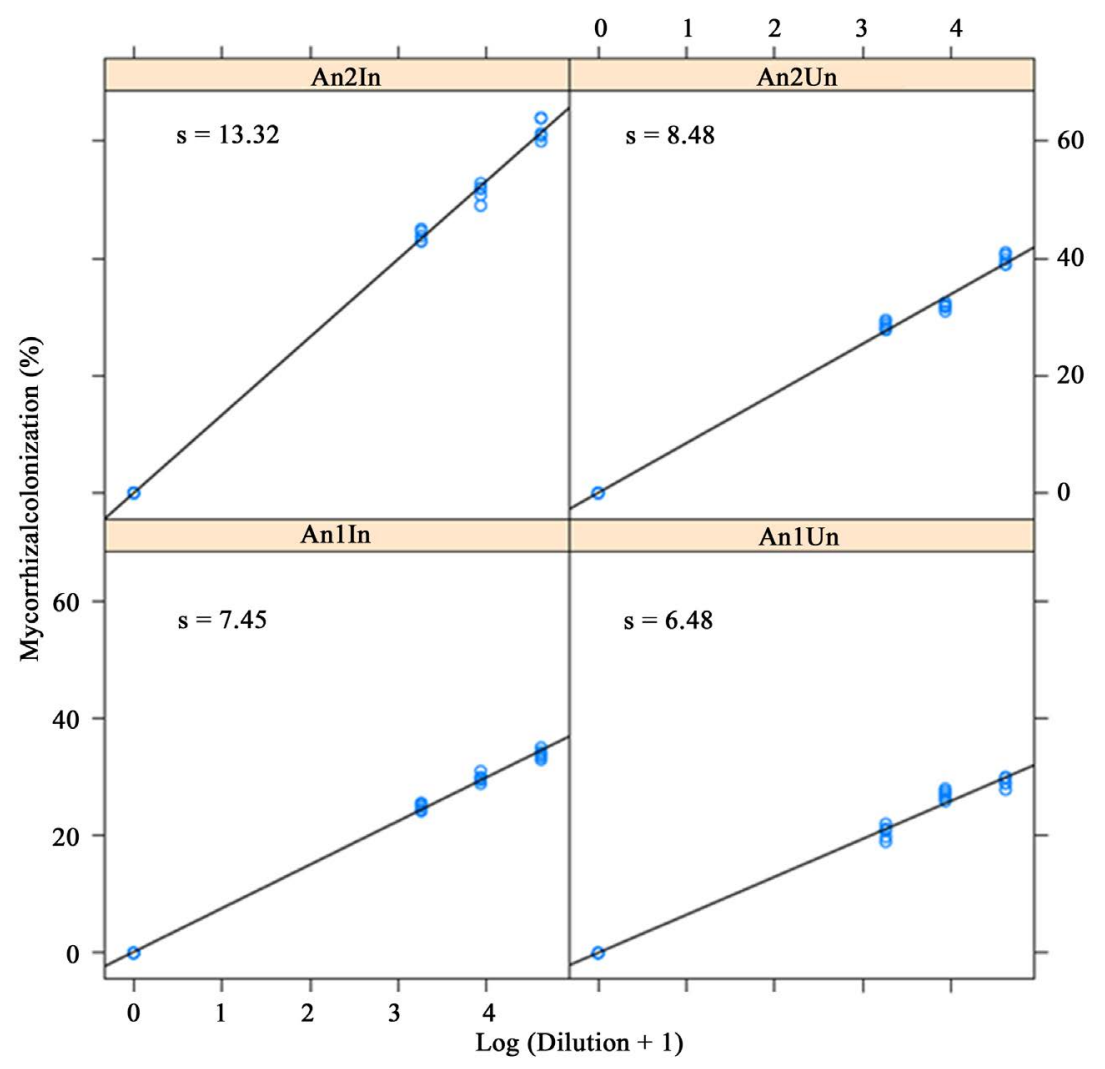

Figure 2. Regression model between log soil dilutions (original cultural soil inoculated or not with $R$. irregularis/autoclaved soil mixture, v:v) and the extent of AM colonization (MC) in each cultural treatment. An1Un and An2Un: Uninoculated soil after 1 year and 2 years cultivation, respectively. An1In and An2In: inoculated soil with $R$. irregularis after 1 year and 2 years cultivation, respectively.

3) Microbial catabolic diversity represents another important microbial trait, commonly used to investigate soil functioning [43]. As already reported in previous studies [13] [31] [44], our results show that AMF inoculation was accompanied with an increase of the soil catabolic eveness. This increase is related to a better soil functioning by enhancing the resistance of soils to stress and disturbance [45]-[47]. The main differences among the patterns of in situ catabolic potential (ISCP) were detected with some carboxylic acids. It is well known that among the identified carboxylic acids, dicarboxylic (oxalic, tartaric, malic, fumaric, malonic acids) and tricarboxylic acids (citric acid) were effective in phosphorus mobilization [48]. It also has been reported that gluconic acid was the most frequent inorganic compound for mineral phosphate solubilisation [49]. SIR responses with all these organic acids were the highest in the AMF inoculation treatment. It suggests that these AMF and their associated hyphosphere microflora excreted higher amounts of such organic acids. These organic compounds could exert a selective influence on soil microbial communities through a multiplication of microorganisms with abilities to catabolize organic acids.

\section{Conclusion}

In conclusion, this study confirms that field AMF inoculation can be proposed as an effective agronomic practice in wheat production and in a sustainable cultural practice to manage the soil biofunctioning. In order to fully profit inoculation, a better knowledge on the AMF ecology has to be acquired in order to predict under which environmental conditions, AMF inoculation will promote yield and agricultural sustainability.

\section{Acknowledgements}

This study was funded by the project Fabatropimed supported by Agropolis Foundation under the reference ID 1001-009. 


\section{References}

[1] Smith, S.E. and Read, D.J. (2008) Mycorrhizal Symbiosis. 3rd Edition, Academic Press, Amsterdam.

[2] van der Heijden, M.G.A., Klironomos, J.N., Ursic, M., Moutoglis, P., Streitwolf-Engel, R., Boller, T., Wiemken, A. and Sanders, I.R. (1998) Mycorrhizal Fungal Diversity Determines Plant Biodiversity, Ecosystem Variability and Productivity. Nature, 396, 72-75. http://dx.doi.org/10.1038/23936

[3] Klironomos, J.N., McCune, J., Hart, M. and Neville, J. (2000) The Influence of Arbuscular Mycorrhizae on the Relationship between Plant Diversity and Productivity. Ecology Letters, 3, 137-141. http://dx.doi.org/10.1046/j.1461-0248.2000.00131.x

[4] O’Connor, P.J., Smith, S.E. and Smith, F.A. (2002) Arbuscular Mycorrhizas Influence Plant Diversity and Community Structure in a Semiarid Herbland. New Phytologist, 154, 209-218. http://dx.doi.org/10.1046/j.1469-8137.2002.00364.X

[5] West, H.M. (1996) Influence of Arbuscular Mycorrhizal Infection on Competition between Holcus lanatus and Dactylis glomerata. Journal of Ecology, 84, 429-438. http://dx.doi.org/10.2307/2261204

[6] Marler, M.J., Zabinski, C.A. and Callaway, R.M. (1999) Mycorrhizae Indirectly Enhance Competitive Effects of an Invasive Forb on a Native Bunchgrass. Ecology, 80, 1180-1186. http://dx.doi.org/10.1890/0012-9658(1999)080[1180:MIECEO]2.0.CO;2

[7] van der Heijden, M.G.A., Wiemken, A. and Sanders, I.R. (2003) Different Arbuscular Mycorrhizal Fungi Alter Coexistence and Resource Distribution between Co-Occurring Plant. New Phytologist, 157, 569-578. http://dx.doi.org/10.1046/j.1469-8137.2003.00688.x

[8] Rambelli, A. (1973) The Rhizosphere of Mycorrhizae. In: Marks, G.C. and Kozlowski, T.T., Eds., Ectomycorrhizae: Their Ecology and Physiology, Academic Press, New York, 299-343. http://dx.doi.org/10.1016/b978-0-12-472850-9.50014-1

[9] Leyval, C. and Berthelin, J. (1993) Rhizodeposition and Net Release of Soluble Compounds by Pine and Beech Seedlings Inoculated with Rhizobacteria and Ectomycorrhizal Fungi. Biology and Fertility of Soils, 15, 259-267. http://dx.doi.org/10.1007/BF00337210

[10] Linderman, R.G. (1988) Mycorrhizal Interactions with the Rhizosphere Microflora: The Mycorrhizosphere Effect. Phytopathology, 78, 366-371.

[11] Linderman, R.G. (2008) The Mycorrhizosphere Phenomenon. In: Feldman, F., Kapulnik, Y. and Barr, J., Eds., Mycorrhiza Works, Deutsche Phytomedizinische Gesellschaft, Braunschweig, 341-355.

[12] Johansson, J.F., Paul, L.R. and Finlay, P.R. (2004) Microbial Interactions in the Mycorrhizosphere and Their Significance for Sustainable Agriculture. FEMS Microbiology and Ecology, 48, 1-13. http://dx.doi.org/10.1016/j.femsec.2003.11.012

[13] Duponnois, R., Colombet, A., Hien, V. and Thioulouse, J. (2005) The Mycorrhizal Fungus Glomus intraradices and Rock Phosphate Amendment Influence Plant Growth and Microbial Activity in the Rhizosphere of Acacia holosericea. Soil Biology and Biochemistry, 37, 1460-1468. http://dx.doi.org/10.1016/j.soilbio.2004.09.016

[14] Artursson, V., Finlay, R.D. and Jansson, J.K. (2006) Interactions between Arbuscular Mycorrhizal Fungi and Bacteria and Their Potential for Stimulating Plant Growth. Environmental Microbiology, 8, 1-10. http://dx.doi.org/10.1111/j.1462-2920.2005.00942.x

[15] Klironomos, J.N. (2000) Host-Specificity and Functional Diversity among Arbuscular Mycorrhizal Fungi. In: Bell, C.R., Brylinski, M. and Johnson-Green, P., Eds., Proceedings of the 8th International Symposium on Microbial Ecology, Atlantic Canada Society from Microbial Ecology, Halifax, 845-851.

[16] Munkvold, L., Kjoller, R., Vestberg, M., Rosendahl, S. and Jakobsen, I. (2004) High Functional Diversity within Species of Arbuscular Mycorrhizal Fungi. New Phytologist, 164, 357-364. http://dx.doi.org/10.1111/j.1469-8137.2004.01169.x

[17] Lekberg, Y. and Koide, T. (2005) Is Plant Performance Limited by Abundance of Arbuscular Mycorrhizal Fungi? A Meta-Analysis of Studies Published between 1988 and 2003. New Phytologist, 168, 189-204. http://dx.doi.org/10.1111/j.1469-8137.2005.01490.x

[18] Avio, L., Pellegrino, E., Bonari, E. and Giovannetti, M. (2006) Functional Diversity of Arbuscular Mycorrhizal Fungal Isolates in Relation to Extraradical Mycelial Network. New Phytologist, 172, 347-357. http://dx.doi.org/10.1111/j.1469-8137.2006.01839.x

[19] Wilcox, J. and Makowski, D. (2014) A Meta-Analysis of the Predicted Effects of Climate Change on Wheat Yields Using Simulation Studies. Field Crops Research, 156, 180-190. http://dx.doi.org/10.1016/j.fcr.2013.11.008

[20] Campiglia, E., Mancinelli, R., De Stefanis, E., Pucciarmati, S. and Radicetti, E. (2015) The long-Term Effects of Conventional and Organic Cropping Systems, Tillage Managements and Weather Conditions on Yield and Grain Quality of Durum Wheat (Triticum durum Desf.) in the Mediterranean Environment of Central Italy. Field Crops Research, 
176, 34-44. http://dx.doi.org/10.1016/j.fcr.2015.02.021

[21] Simane, B., Peacock, J.M. and Struik, P.C. (1993) Differences in Developmental Plasticity and Growth Rate among Drought-Resistant and Susceptible Cultivars of Durum Ehat (Triticum turgidum L. var. durum). Plant \& Soil, 157, 155-166. http://dx.doi.org/10.1007/BF00011044

[22] Hetrick, B.A.D., Wilson, G.W.T. and Cox, T.S. (1993) Mycorrhizal Dependence of Modern Wheat Cultivars and Ancestors: A Synthesis. Canadian Journal of Botany, 71, 512-518. http://dx.doi.org/10.1139/b93-056

[23] Pellegrino, E., Opik, M., Bonari, E. and Ercoli, L. (2015) Responses of Wheat to Arbuscular Fungi: A Meta-Analysis of Field Studies from 1975 to 2013. Soil Biology \& Biochemistry, 84, 210-217. http://dx.doi.org/10.1016/j.soilbio.2015.02.020

[24] John, M.K. (1970) Colorimetric Determination in Soil and Plant Material with Ascorbic Acid. Soil Science, 68, 171-177. http://dx.doi.org/10.1097/00010694-197004000-00002

[25] Phillips, J.M. and Hayman, D.S. (1970) Improved Procedures for Clearing Roots and Staining Parasitic and Vesicular-Arbuscular Mycorrhizal Fungi for Rapid Assessment of Infection. Transactions of the British Mycological Society, 55, 158-161. http://dx.doi.org/10.1016/S0007-1536(70)80110-3

[26] Giovanetti, M. and Mosse, B. (1980) An Evaluation of Techniques for Measuring Vesicular Arbuscular Mycorrhizal Infection in Roots. New Phytologist, 84, 489-500. http://dx.doi.org/10.1111/j.1469-8137.1980.tb04556.x

[27] Rubio, R., Borie, F., Schalchli, C., Castillo, C. and Azcon, R. (2003) Occurrence and Effect of Arbuscular Mycorrhizal Propagules in Wheat as Affected by the Source and Amount of Phosphorus Fertilizer and Fungal Inoculation. Applied Soil Ecology, 23, 245-255. http://dx.doi.org/10.1016/S0929-1393(03)00045-3

[28] Degens, B.P. and Harris, J.A. (1997) Development of a Physiological Approach to Measuring the Metabolic Diversity of Soil Microbial Communities. Soil Biology \& Biochemistry, 29, 1309-1320. http://dx.doi.org/10.1016/S0038-0717(97)00076-X

[29] Boudiaf, I., Baudoin, E., Sanguin, H., Beddiar, A., Thioulouse, J., Galiana, A., Prin Y., Le Roux, C., Lebrun, M. and Duponnois R. (2013) The Exotic Legume Tree Species, Acacia mearnsii, Alters Microbial Soil Functionalities and the Early Development of a Native Tree Species, Quercus suber, in North Africa. Soil Biology and Biochemistry, 65, 172-179. http://dx.doi.org/10.1016/j.soilbio.2013.05.003

[30] Magurran, A.E. (1988) Ecological Diversity and Its Measurement. Croom Helm, London.

[31] Kisa, M., Sanon, A., Thioulouse, J., Assigbetse, K., Sylla, S., Spichiger, R., Dieng, L., Berthelin, J., Prin, Y., Galiana, A., Lepage, M. and Duponnopis, R. (2007) Arbuscular Mycorrhizal Symbiosis Can Counterbalance the Negative Influence of the Exotic Tree Species Eucalyptus camaldulensis on the Structure and Functioning of Soil Microbial Communities in a Sahelian Soil. FEMS Microbiology Ecology, 62, 32-44. http://dx.doi.org/10.1111/j.1574-6941.2007.00363.x

[32] Venables, W.N. and Ripley, B.D. (2002) Modern Applied Statistics. Springer, New York. http://dx.doi.org/10.1007/978-0-387-21706-2

[33] R Development Core Team (2010) R: A Language and Environment for Statistical Computing. R Foundation for Statistical Computing, Vienna, Austria. http://www.R-project.org

[34] Pinheiro, J.C. and Bates, D.M. (2000) Mixed-Effects Models in S and S-PLUS. Springer, New York. http://dx.doi.org/10.1007/978-1-4419-0318-1

[35] Ryan, M.H., Chilvers, G.A. and Dumarsq, D.C. (1994) Colonization of Wheat by VA Mycorrhizal Fungi Was Found to Higher on a Farm Managed in an Organic Manner than on a Conventional Neighbour. Plant \& Soil, 160, 33-40. http://dx.doi.org/10.1007/BF00150343

[36] Graham, J.H. and Abbott, L.K. (2000) Wheat Responses to Aggressive and Non-Aggressive Arbuscular Mycorrhizal Fungi. Plant \& Soil, 220, 207-218. http://dx.doi.org/10.1023/A:1004709209009

[37] Duponnois, R. and Plenchette, C. (2003) A Mycorrhiza Helper Bacterium (MHB) Enhances Ectomycorrhizal and Endomycorrhizal Symbiosis of Australian Acacia Species. Mycorrhiza, 13, 85-91. http://dx.doi.org/10.1007/s00572-002-0204-7

[38] Dabire, A.P., Hien, V., Kisa, M., Bilgo, A., Sangare, K.S., Plenchette, C., Galiana, A., Prin, Y. and Duponnois, R. (2007) Responses of Soil Microbial Catabolic Diversity to Arbuscular Mycorrhizal Inoculation and Soil Disinfection. Mycorrhiza, 17, 537-545. http://dx.doi.org/10.1007/s00572-007-0126-5

[39] Xavier, L.J. and Germida, J.J. (1997) Growth Response of Lentil and Wheat to Glomus clarum NT4 over a Range of P Levels in a Saskatchewan Soil Containing Indigenous AM Fungi. Mycorrhiza, 7, 3-8. http://dx.doi.org/10.1007/s005720050156

[40] Al-Karaki, G.N. and Clark, R.B. (1999) Mycorrhizal Influence on Protein and Lipid of Durum Wheat Grown at Different Soil Phosphorus Levels. Mycorrhiza, 9, 97-101. http://dx.doi.org/10.1007/s005720050006 
[41] Lehmann, A., Barto, K., Powell, J.R. and Rillig, M.C. (2012) Mycorrhizal Responsiveness Trends in Annual Crop Plants and Their Wild Relatives: A Meta-Analysis on Studies from 1981 to 2010. Plant \& Soil, 355, 231-250. http://dx.doi.org/10.1007/s11104-011-1095-1

[42] Verbruggen, E., van der Heijden, M.G.A., Rillig, M.C. and Kiers, E.T. (2012) Mycorrhizal Fungal Establishment in Agricultural Soils: Factors Determining Inoculation Success. New Phytologist, 197, 1025-1026.

[43] Romina Romaniuk, R., Giuffré, L., Costantini, A. and Nannipieri, P. (2011) Assessment of Soil Microbial Diversity Measurements as Indicators of Soil Functioning in Organic and Conventional Horticulture Systems. Ecological Indicators, 11, 1345-1353. http://dx.doi.org/10.1016/j.ecolind.2011.02.008

[44] Bilgo, A., Sangare, K.S., Thioulouse, J., Prin, Y., Hien, V., Galiana, A., Baudoin, E., Hafidi, M., Bâ, A.M. and Duponnois, R. (2011) Response of Native Soil Microbial Functions to the Controlled Mycorrhization of an Exotic Tree Legume, Acacia holosericea in a Sahelian Ecosystem. Mycorrhiza, 22, 175-187. http://dx.doi.org/10.1007/s00572-011-0390-2

[45] Giller, K.E., Beare, M.H., Lavelle, P., Izac, A.M.N. and Swift, M.J. (1997) Agricultural Intensification, Soil Biodiversity and Agrosystem Function. Applied Soil Ecology, 6, 3-16. http://dx.doi.org/10.1016/S0929-1393(96)00149-7

[46] Degens, B.P. (1998) Decreases in Microbial Functional Diversity Do Not Result in Corresponding Changes in Decomposition under Different Moisture Conditions. Soil Biology \& Biochemistry, 30, 1989-2000. http://dx.doi.org/10.1016/S0038-0717(98)00071-6

[47] Degens, B.P., Schipper, L.A., Sparling, G.P. and Duncan, L.C. (2001) Is the Microbial Community in a Soil with Reduced Catabolic Diversity Less Resistant to Stress or Disturbance? Soil Biology \& Biochemistry, 33, 1143-1153. http://dx.doi.org/10.1016/S0038-0717(01)00018-9

[48] Ryan, P.R., Delhaise, E. and Jones, D.L. (2001) Function and Mechanism of Organic Anion Exudation from Plant Roots. Annual Review of Plant Physiology, 52, 527-560. http://dx.doi.org/10.1146/annurev.arplant.52.1.527

[49] Illmer, P. and Schinner, F. (1992) Solubilization of Inorganic Phosphate by Microorganisms Isolated from Forest Soil. Soil Biology \& Biochemistry, 24, 389-395. http://dx.doi.org/10.1016/0038-0717(92)90199-8 